\title{
A Novel FERM Domain Including Guanine Nucleotide Exchange Factor Is Involved in Rac Signaling and Regulates Neurite Remodeling
}

\author{
Tateki Kubo, ${ }^{1,2,3}$ Toshihide Yamashita, ${ }^{1,3}$ Atsushi Yamaguchi, ${ }^{1,3}$ Hideki Sumimoto, ${ }^{4}$ Ko Hosokawa, ${ }^{2}$ and \\ Masaya Tohyama ${ }^{1,3}$ \\ Departments of ${ }^{1}$ Anatomy and Neuroscience and ${ }^{2}$ Plastic Surgery, Osaka University Graduate School of Medicine, Suita, \\ Osaka, 565-0871, Japan, ${ }^{3}$ Core Research for Evolutional Science and Technology of Japan Science and Technology \\ Corporation, Kawaguchi, Saitama, 332-0012, Japan, and ${ }^{4}$ Medical Institute of Bioregulation, Kyushu University, \\ Higashi-ku, Fukuoka 812-8582, Japan
}

\begin{abstract}
The Rho family of small GTPases, key regulators of the actin cytoskeleton in eukaryotic cells from yeast to human, is implicated in the control of neuronal morphology. Guanine nucleotide exchange factors (GEFs) are upstream positive regulators of Rho GTPases and integrate extracellular signaling for appropriate activation of Rho GTPases at specific subcellular regions. Here we describe the identification of a novel Dbl family GEF for Rho GTPases in Homo sapiens and Mus musculus. It contains a tandem Dbl homology-pleckstrin homology domain and FERM domain, characteristic of the plasma membrane proteins linker. This gene, termed FERM domain including RhoGEF (FIR), was abundantly expressed in brain, lung, and
\end{abstract}

The Rho GTPases are key regulators of the actin cytoskeleton in eukaryotic cells from yeast to human (Hall, 1998) and mediate the morphological changes that can be observed during neuronal development and plasticity, such as growth of neurites, axon guidance, and dendrite elaboration (Luo et al., 1994; Threadgill et al., 1997; Yamashita et al., 1999; Li et al., 2000). Each member of the archetypal trio of the Rho GTPases, RhoA, Rac1, and $\mathrm{Cdc} 42$, has been found to regulate distinct actin filamentcontaining structures. RhoA regulates the formation of focal adhesions and subsequent assembly of stress fibers, and Rac1 regulates the formation of membrane lamellae, whereas $\mathrm{Cdc} 42$ triggers the outgrowth of peripheral spike-like protrusions known as filopodia (van Aelst and D'Souza-Schorey, 1997; Hall, 1998; Richnau and Aspenstrom, 2001). The potential of the Rho GTPases to function as signaling switches resides in their ability to cycle between active, GTP-bound states and inactive, GDPbound states. These cyclings are regulated by a variety of intracellular proteins. GTPase-activating proteins stimulate the intrinsic GTP hydrolysis of the GTPases, thus inactivating their targets (Lamarche and Hall, 1994; Whitehead et al., 1997; Zalcman et al., 1999). Guanine nucleotide exchange factors (GEFs) promote the exchange of GDP for GTP, thereby activating GTPases. The Rho

\footnotetext{
Received April 2, 2002; revised June 10, 2002; accepted July 8, 2002.

We thank Yumiko Hara and Akemi Arakawa for participating in this work.

Correspondence should be addressed to Dr. Toshihide Yamashita, Department of Anatomy and Neuroscience, Osaka University Graduate School of Medicine, 2-2 Yamadaoka, Suita, Osaka 565-0871, Japan. E-mail: tyama@anat2.med.osakau.ac.jp.

Copyright (C) 2002 Society for Neuroscience $\quad 0270-6474 / 02 / 228504-10 \$ 15.00 / 0$
}

testis, as well as embryonic hippocampal and cortical neurons. FIR was found to activate the biochemical pathway specific for Rac1 but not for RhoA or Cdc42. Ectopic expression of FIR in the cortical neurons resulted in significantly shortened neurites and excessive growth cones, presumably mediated by Rac1. These results suggest that FIR may regulate neurite remodeling by mediating the signaling pathways from membrane proteins to Rac.

Key words: Rac1; Rho guanine nucleotide exchange factor; FERM domain; cytoskeleton; neurite outgrowth; neuronal morphology

GEFs comprise enzymes with Dbl homology (DH) domain (Mackay and Hall, 1998) and are Rho GTPase-specific exchange factors (Whitehead et al., 1997). These proteins are characterized by a DH domain sharing $\sim 250$ amino acids (aa), followed immediately by a pleckstrin homology $(\mathrm{PH})$ domain (Stam and Collard, 1999). They often contain multiple protein motifs, such as Src homology domains 2 and 3 and PDZ (postsynaptic density 95/ Discs large/zona occludens 1) domains, most of which are involved in intracellular signal transduction (Matsuo et al., 2002). GEFs from the Dbl family are thought to integrate extracellular signaling for appropriate activation of Rho GTPases at specific subcellular regions. Whereas in Caenorhabditis elegans and Drosophila some GEFs from the Dbl family have been shown to play essential roles in neurite genesis (Steven et al., 1998; Awasaki et al., 2000; Bateman et al., 2000; Liebl et al., 2000; Newsome et al., 2000), in vertebrates, little is known about regulations of neurite outgrowth by GEFs (Kunda et al., 2001; Penzes et al., 2001; Matsuo et al., 2002).

To further understand the molecular mechanisms underlying the activation of Rho GTPases and biological phenomena that the related signaling pathway regulates, especially in neurons, we tried to identify a novel GEF using a consensus sequence for $\mathrm{DH}$ domains of Rho guanine nucleotide exchange factors to search DNA databases. Here we describe the identification of a novel GEF for Rho GTPases, including FERM domain in Homo sapiens and Mus musculus. These proteins, termed FERM domain including RhoGEF (FIR), were found to activate the biochemical pathway specific for Rac1. Ectopic expression of FIR in cortical neurons resulted in morphological changes. 


\section{MATERIALS AND METHODS}

RNA isolation and Northern blot analysis. Total RNA derived from 6-week-old adult mice was extracted from various tissues by the acid guanidium-thiocyanate-phenol chloroform method. Total RNA $(20 \mu \mathrm{g} /$ lane) was separated by electrophoresis on $1.0 \%$ agarose-formide gels and transferred overnight onto polyvinylidene difluoride membrane (Millipore, Bedford, MA). The membrane was prehybridized for $1 \mathrm{hr}$ at $65^{\circ} \mathrm{C}$ in hybridization buffer $(0.9 \mathrm{M} \mathrm{NaCl}$ and $90 \mathrm{~mm}$ sodium citrate, $\mathrm{pH}$ 7.0) containing $5 \times$ Denhardt's solution, $0.5 \%$ SDS, and heat-denatured salmon sperm DNA $(100 \mathrm{ng} / \mathrm{ml})$. The cDNA probe specific for mouse FIR mRNA was radiolabeled with $\left[{ }^{32} \mathrm{P}\right] \mathrm{dCTP}$ (NZ522; PerkinElmer Life Sciences, Emeryville, CA) by a random labeling kit according to the instructions of the manufacturer (Takara Shuzo, Shiga, Japan). After hybridization overnight at $65^{\circ} \mathrm{C}$ in hybridization buffer containing radiolabeled cDNA probe $(5 \mathrm{ng} / \mathrm{ml})$, the membrane was washed with $2 \times$ SSC containing $0.5 \%$ SDS, followed by $0.2 \times$ SSC containing $0.5 \%$ SDS, each for $30 \mathrm{~min}$ at $65^{\circ} \mathrm{C}$. Then, the filters were exposed to x-ray films (Fujifilm, Tokyo, Japan) and subjected to autoradiography.

Reverse transcription-PCR. Total RNA $(5 \mu \mathrm{g})$ was reverse-transcribed using oligo-dT by reverse transcriptase from Moloney murine leukemia virus (Invitrogen, San Diego, CA). For PCR amplification, specific oligonucleotide primer pairs $(10 \mathrm{pmol}$ each) were incubated with $1 \mu \mathrm{l}$ of cDNA template in a $20 \mu \mathrm{l}$ PCR reaction mixture containing $1.5 \mathrm{~mm}$ $\mathrm{MgCl}_{2}, 25 \mathrm{~mm} \mathrm{KCl}, 10 \mathrm{~mm}$ Tris, $\mathrm{pH} 9.2$, mixed deoxynucleotides (1 mM each), and $1 \mathrm{U}$ of Taq polymerase. The sequences of primers used were as follows: mouse FIR sense primer, 5'-AATTGACGGAGCTACAGCGA$3^{\prime}$ and mouse FIR antisense primer, 5'-GACGTGAGATTTGAATTGGA-3' (product length, $801 \mathrm{bp}$ ); mouse glial fibrillary acidic protein (GFAP) sense primer, 5'-TAGACAGGAGGCAGATGAAGCCACC-3' and mouse GFAP antisense primer, 5'-GTCGTTAGCTTCGTGCTTGGCTTGG-3' (product length, $337 \mathrm{bp}$ ); and, as an internal control, mouse $\beta$-actin sense primer, $5^{\prime}$ - TCCTCCCTGGAGAAGAGCTA- $3^{\prime}$ and mouse $\beta$-actin antisense primer, $5^{\prime}$-TCCTGCTTGCTGATCCACAT-3' (product length, $403 \mathrm{bp}$ ). Dilutions of the cDNAs were amplified for 35 cycles at $94^{\circ} \mathrm{C}$ for $30 \mathrm{sec}, 60^{\circ} \mathrm{C}$ for $30 \mathrm{sec}$, and $72^{\circ} \mathrm{C}$ for $30 \mathrm{sec}$. The amplified PCR products were analyzed by $1.2 \%$ agarose gel electrophoresis and ethidium bromide staining. The product for $\beta$-actin mRNA served as the internal standard. All of the products were assayed in the linear response range of the reverse transcription (RT)-PCR amplification process; the cycle number used was determined by finding the midpoint of linear amplification on a sigmoid curve for amplification products with cycle numbers of 24-40 plotted against band density. The identity of each PCR product was confirmed by subcloning the amplified cDNAs into the pGEM-T vector (Promega, Madison, WI) and sequencing.

Plasmid constructs. The full-length FIR (FL-FIR) cDNA (KIAA0793; gifts from Dr. T. Nagase, Kazusa DNA Research Institute, Kisarazu, Japan) was digested with $S a l \mathrm{I}$ and $\mathrm{Xba \textrm {I }}$ and subcloned into pEGFP plasmid (Clontech, Palo Alto, CA), which produces the N-terminally green fluorescent protein (GFP)-tagged protein under the control of cytomegalovirus promoter. N-terminal truncated FIR $(\Delta \mathrm{N}-\mathrm{FIR}$; aa $346-$ 1055) was generated by digestion of the full-length FIR with SacI and $X$ hoI and subcloned into pEGFP plasmid. The $720 \mathrm{bp}$ fragment encoding the DH domain of FIR (aa 516-755) and the 942 bp fragment encoding the DH and PH domains of FIR (aa 540-853) were subcloned into the EcoRI and XhoI sites of pGEX-5X (Amersham Biosciences, Arlington Heights, IL). Wild-type Rac1, Cdc42, and RhoA were N-terminally hemagglutinin (HA) tagged and subcloned into the pcDNA3 (Invitrogen). Rac1-61L, Rac1-17N, and RhoA-19N in pEF-BOS and wild-type Rac1 and RhoA in pGEX-4T to produce glutathione $S$-transferase (GST) fusion proteins in Escherichia were gifts from Dr. A. Hall (Department of Biochemistry and Molecular Biology, University College London, London, UK). Wild-type Cdc42 was subcloned into pGEX-5X (Amersham Biosciences). The construct for Rac-binding domain of human PAK2 (PAK2-RBD; aa 66-147) in PGEX-4T was made as described previously (Akasaki et al., 1999). The construct for GST fusion to the RhoA binding domain of Rhotekin (GST-RBD) was a gift from Dr. M. A. Schwartz (Department of Cell Biology, The Scripps Research Institute, La Jolla, CA), and neural Wiskott-Aldrich syndrome protein (NWASP)-Cdc42/Rac1 interactive binding (CRIB) in pEF-BOS was from Dr. T. Takenawa (Division of Biochemistry, Institute of Medical Science, University of Tokyo, Tokyo, Japan).

Expression and purification of recombinant proteins. Bacterially expressed recombinant RhoA, Rac1, Cdc42, and FIR proteins were purified as described previously (Chuang et al., 1995). Escherichia strain DH5 $\alpha$ transformed with the vectors was treated for $3 \mathrm{hr}$ at $37^{\circ} \mathrm{C}$ with 0.1
$\mathrm{mM}$ isopropyl-thio- $\beta$-D-galactoside to induce the expression of each protein, which was purified through a glutathione-Sepharose 4B column.

In vitro nucleotide exchange assay. Purified Rho proteins were used directly for the ${ }^{3} \mathrm{H}$-loaded GDP dissociation assays as described previously (Horii et al., 1994; Chuang et al., 1995). Briefly, $4 \mu \mathrm{g}$ of each Rho GTPase was incubated with $10 \mu \mathrm{M}\left[{ }^{3} \mathrm{H}\right] \mathrm{GDP}$ (PerkinElmer Life Sciences) for $25 \mathrm{~min}$ at room temperature, and GST-fused DH domain or DH-PH domain of FIR was added to the assay mixture. At the indicated time, an aliquot of the reaction sample was removed and passed through nitrocellulose filters (IPVH 000; Millipore). The filters were washed and used for scintillation counting. GST protein or the buffer was used as a control.

Interaction of FIR with Rho GTPases. Binding of FIR to nucleotide-free Rho GTPases was determined according to the procedure mentioned by Penzes et al. (2001). Briefly, GST fusion proteins of Rho GTPases purified from Escherichia were depleted of bound nucleotide by incubation with 10 mM EDTA. HEK293 cells expressing GFP- $\Delta$ N-FIR, which contains DH and PH domains of FIR, were lysed in binding buffer (40 $\mathrm{mm}$ Tris- $\mathrm{HCl}, \mathrm{pH} 7.5$, and $50 \mathrm{~mm} \mathrm{NaCl}$ containing $1 \%$ Triton $\mathrm{X}-100$ ). For each binding reaction, $5 \mu \mathrm{g}$ of GST-GTPase bound to $25 \mu \mathrm{l}$ of glutathione-Sepharose beads was mixed with an aliquot of cell extract containing $1 \mathrm{mg}$ of protein for $2 \mathrm{hr}$ at $4^{\circ} \mathrm{C}$. The beads were washed with binding buffer, and bound proteins were analyzed by SDS-PAGE and Western blotting using the monoclonal anti-GFP antibody (Santa Cruz Biotechnology, Santa Cruz, CA).

Pull-down GTPase assay. In vivo $\mathrm{Rac} 1 / \mathrm{Cdc} 42$ activation assay was performed according to the method we described previously (Akasaki et al., 1999). HEK293T cells were transfected using Lipofectamine2000 (Invitrogen, Gaithersburg, MD), cultured for $48 \mathrm{hr}$, and lysed [in 20 mM HEPES, pH 7.4, $150 \mathrm{~mm} \mathrm{NaCl}$, 2\% Nonidet P-40, 20\% glycerol, 8 mM EGTA, 8 mм EDTA, $80 \mu \mathrm{M} p$-amidinophenylmethanesulfonyl fluoride (hydrochloride), $100 \mu \mathrm{g} / \mathrm{ml}$ aprotinin, and $200 \mu \mathrm{g} / \mathrm{ml}$ each of leupeptin, chymostatin, and pepstatin A]. Cell lysates were clarified by centrifugation, and the supernatant was incubated with 20 $\mu \mathrm{g}$ of GST-PAK2 protein immobilized on glutathione-Sepharose beads for $3 \mathrm{~min}$. Beads were washed with washing buffer (20 mM HEPES, pH 7.4, $142.5 \mathrm{~mm} \mathrm{NaCl}, 1 \%$ Nonidet P-40, $10 \%$ glycerol, 4 mM EGTA, and 4 mM EDTA), and bound GTP-Rho proteins were detected by Western blotting with the anti-HA monoclonal antibody (Boehringer Mannheim, Mannheim, Germany). In vivo RhoA activity assay was performed according to the method reported by Schwartz and his colleagues using a GST fusion to the RhoA binding domain of Rhotekin (GST-RBD) (Ren et al., 1999). To detect endogenous Rac1 activation by FIR, COS-7 cells were cultured for $24 \mathrm{hr}$ after transfection, followed by the pull-down assay.

In vivo nucleotide labeling. Transfected HEK293T cells were cultured for $24 \mathrm{hr}$, serum starved in DMEM medium, labeled with $\left[{ }^{32} \mathrm{P}\right]$ orthophosphate $(100 \mu \mathrm{Ci} / \mathrm{ml}$; PerkinElmer Life Sciences) for $4 \mathrm{hr}$, and disrupted in lysis buffer (50 mM Tris- $\mathrm{HCl}, \mathrm{pH} 7.5,20 \mathrm{~mm} \mathrm{MgCl}_{2}, 150 \mathrm{~mm}$ $\mathrm{NaCl}, 0.5 \%$ Nonidet-P40, $1 \mathrm{~mm}$ sodium orthovanadate, $1 \mathrm{~mm}$ PMSF, 25 $\mu \mathrm{g} / \mathrm{ml}$ leupeptin, and $25 \mu \mathrm{g} / \mathrm{ml}$ aprotinin). Lysates were immunoprecipitated with the anti-HA monoclonal antibody for $2 \mathrm{hr}$ using protein Sepharose $\mathrm{G}$ beads (Amersham Biosciences). Immunoprecipitates were washed three times in lysis buffer and twice in washing buffer $(50 \mathrm{~mm}$ Tris- $\mathrm{HCl}$, pH 7.5, $20 \mathrm{~mm} \mathrm{MgCl}_{2}$, and $500 \mathrm{~mm} \mathrm{NaCl}$ ) and finally were resuspended in $1 \mathrm{M} \mathrm{KH}_{2} \mathrm{PO}_{4}, \mathrm{pH}$ 3.4. Bound nucleotides were released by heating at $68^{\circ} \mathrm{C}$ and fractionated using polyethyleneimine thin-layer chromatography plates. Radioactive spots, located by autoradiography, were scraped off the plates and counted in a scintillation counter (Yamashita et al., 1999).

Cell cultures and transient transfections. NIH3T3cells and COS-7cells were cultured in DMEM containing $10 \%$ fetal bovine serum (Sigma St. Louis, MO), penicillin, and streptomycin. For immunocytochemistry, cells grown on chamber slides for $3 \mathrm{~d}$ to $40-60 \%$ confluence were transfected with $0.15 \mu \mathrm{g}$ of plasmid DNA per $1 \mathrm{~cm}^{2}$ and $0.25 \mu \mathrm{l} / \mathrm{cm}^{2}$ Lipofectamine2000 in complete serum-free medium for $5 \mathrm{hr}$, after which they were washed and fed with growth medium for $24 \mathrm{hr}$. Then, the medium was replaced with DMEM without serum for $16 \mathrm{hr}$. Cells fixed in $4.0 \%$ formaldehyde in PBS $(50 \mathrm{~mm} \mathrm{NaPi}, \mathrm{pH} 7.5$, and $150 \mathrm{~mm}$ $\mathrm{NaCl}$ ) for $10 \mathrm{~min}$ at room temperature were permeabilized and stained.

Neuronal cultures and transfections. Cerebral cortex from embryonic day 18 rat was digested with papain for $30 \mathrm{~min}$ at $37^{\circ} \mathrm{C}$, followed by dissociation. Dissociated neurons were plated on the dishes precoated with poly-L-lysine in DMEM containing 10\% fetal bovine serum (Sig- 
ma), penicillin, and streptomycin. After culturing for $1 \mathrm{~d}$, the medium was replaced with DMEM with B-27 supplement. Two days after dissociation, cultures from rat embryo were transfected using Lipofectamine2000. The neurons were fixed $24 \mathrm{hr}$ after transfection in $4.0 \%$ formaldehyde for $20 \mathrm{~min}$, permeabilized, and blocked in PBS containing $5 \%$ normal goat serum, $0.1 \%$ bovine serum albumin, and $0.1 \%$ Triton $\mathrm{X}-100$ for $30 \mathrm{~min}$. The cultures were incubated overnight with the monoclonal antibody to class III $\beta$-tubulin (Research Diagnostics, Flanders, NJ), followed by Alexa Fluor-conjugated secondary antibody (Molecular Probes, Eugene, OR). Morphological features were quantified using LSM510 software version 2.02 (Zeiss, Oberkochen, Germany). Pictures of randomly selected fields were taken at low magnification, and the total neurite length as well as the length of the longest process on each individual neuron in the field was measured after it was traced using the computer program; at least 40 neurons from three independent cultures were analyzed.

Dissociated cultures of hippocampus from embryonic day 18 mouse were performed by the same procedure mentioned above. The hippocampal and the cortical neurons were maintained for $1 \mathrm{~d}$ after dissociation, and total RNA was isolated from them to perform RT-PCR.

\section{RESULTS}

\section{Identification of a novel FERM domain including guanine nucleotide exchange factor for Rho GTPases}

We first intended to identify candidate GEFs for Rho GTPases, which contain domains previously implicated in signal transduction, and searched DNA databases using a consensus amino acid sequence of the DH domain of known GEFs for Rho GTPases (Boguski and McCormick, 1993; Fukuhara et al., 1999). A number of yet uncharacterized proteins containing putative $\mathrm{DH}$-like domains were detected. Subsequently, we analyzed their DNA sequences, and their expected translational products suggested that many of them encode putative GEFs for Rho GTPases. We were interested in one of them, KIAA0793, human cDNA clone (GenBank accession number AB018336). The plasmid construct for KIAA0793 was a gift from Dr. T. Nagase, and its nucleotide sequence was confirmed. The cDNA is 3165 bp long and encodes

\section{A}

Figure 1. FIR contains several domains in signal transduction. $A$, Schematic structure and deduced amino acid sequence of human and mouse FIR. The sequences of human and mouse FIR were optimally aligned on the basis of residue identity (nonboxed) and similarity ( gray box). Black boxes are nonconserved residues. FERM domain, Single underline; DH domain, interrupted line; two PH domains, dotted lines. $B, C$, Sequence comparison of FIR with ERM proteins, Dbl, and pleckstrin $(B)$ and other Rac-GEFs $(C)$. Black boxes, Identical residues; gray boxes, similar residues to FIR. hFIR, Human FIR; mFIR, mouse FIR; hSOS1, human SOS1; hTiam1, human Tiam1; hVav1, human Vav1.

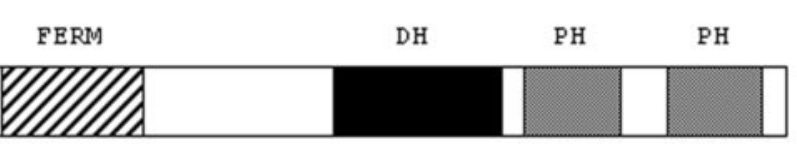

hFIR

MF IR

hF IR

mF IR

hF IR

MF IR

hF IR

MF IR

hF IR

MF IR

hF IR

hF IR

$\mathrm{mF}$ IR

$h F$ IR

hF IR

MFIR

hF IR

MF IR

hF IR

hF IR

MF IR

$\underset{\text { mF IR }}{\mathrm{hF}}$

$\underset{m F}{h F}$ IR

$\underset{m F}{h F}$ IR

$\underset{m F}{h F}$ IR

hF IR

hF IR

mF IR

$\mathrm{hF}_{\mathrm{mF}}$ IR
1 MGE IEGTYRVLOT AGURLGQOTPVGUSTLEPGOTUAPRMOE KHL HL RVKLL DNTME IFD

1 MGE IEGTYR AL PT SGTRLGGQTA IGVSTLEPEQSLSP RMQE KHMRI RVKLLDSTVELFD

60 IEPKCDGOVLLTOVUKRLNLVECD YF GMEFONTQSYW I UL EPMKP I IROIRRP KNVVLR 60 IEPKCDGQVLL TQVUKHLNL IECD YF GL E FKNUQSYU IULEPMKP I IRQVRKP KNAVLR

119 LAVKF FPPDPGQLQEEYTRYLF ALQL KRDLLEERL TCADT T AALLTSHLLQSE IGDYDE 119 LAVKF FP PDPGQLQEE YTRYLF ALQLKRDLLEERL TCT ANT A.LLISHLLQSE IGDYDE

178 TLDREHLKVNEYL PGQQHCLEKILEF HOKHVGQTP AESDF OVLE IARKLEMYGIRFHMA 178 TLDREHL KANEYL PNQE KSLEK ILDF HQRHTGQTP AESDF QVLE IARKLEMYGIRFHMA

237 SDREGTKIQL AVSHMGVLVFQGTTK INTFNWSKVRKLSF KRKRF LI KL HPEVHGP YQDT 237 SDRE GTK INL AVSHMGVLVF QGTTK INTFNUSKVRKLSF KRKRFL IKL HP EVHGPYOD T

296 LEFLLGSRDECKNFWKICVE YHTFFRLLDQP KPKAKAVF F SRGSSFRYSGRTQKQLVDY 296 LEF LL GSRDEC KINWK ICVE YHTF FRLSDQP KPKAKAVF F SRGSSF RYSGRTQKQLVDY 355 FKD SGMRRIPYERRHSKTHTSVRALT ADLPKQSISF PEGLRTP ASPSSSAN-AF YSLSPS 413 TLVPSGLPEF KDSSSSLTDPQVSYVKSP A AERRSG- DUAGGPDTPS AOPQGPPALOPGP 414 SLSPPGLPNL KDSSSSLVDPQAPVIKSTAAERSSGPSSSDGPSTQS AHLFGPPVLRP GP 471 GLSUKSPQPSPSSIEKSPLSLSPAFQVPLGPAEQGSSPLLSPVLSDAGG MEMDU-EEPRH 473 GFSHDSPQPSPSSLKSHLSLCPELQAALTAEQGASPVLSPVLSGAGT ARMDNGEEQKH 529 KRVPADEAYF IVKEILATERTYLKDLEVITVWF RSAVVKEDAMP ATLMTLLF SN IDP IY

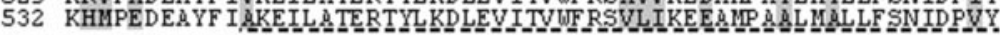
588 EFHRGFL REVEQRLALWEGPSKAHYKGSHQR I GD ILLRNMRQL KEF TSYF QRHDEVLTE 591 EFHRGFL HEVEQRLALLUEGPSS AHL KGD HQRIGDILLLNNMRQLKEF TSYFQRHDEVLTE 647 LEKATKRCKKLEAVYKEF ELQKVCYLPLNTFLL KPIORLL HYRLLLRRLCGHYSPGHHD 650 LEKATKHCKKLEAVYKEFELQKVCYLPLNTFLLKPVQRLVHYRLLLSRLCAHYSPGHRD. 706 YADCHD ALKA ITEVTTTLOHITL IRLENL QKL TELQRDLVGIENL I APGREF IREGCLHK

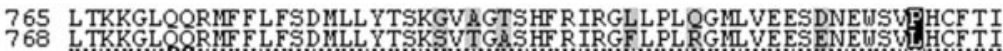
824 YAMOKTIVVAASTRLEKEKWMLDLNS A IQAAKSGGDTAP ALPGRTVCTRPPRSPNEVSL

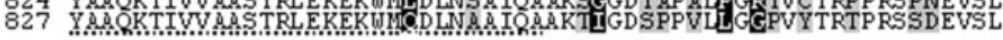
883 EQESEDD ARGERSSLEGHGQHRANTTMHVCWYRNTSVSRADHSAAVENQLSGYLLRKFK

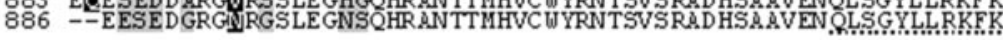
942 NSHGWOKLWVVF TNF CLFF YKTHODD YPLASLPLLGYSVS IPREADG I HKD YVF KLOFK

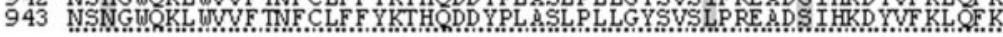
1001 SHVYFFRAESKYTFERWMEVIOGASSSAGRAPSIVODGPOPSSGLEGMVRKEA

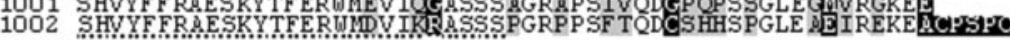

Figure 1 continues. 


\section{B}

FERM domain

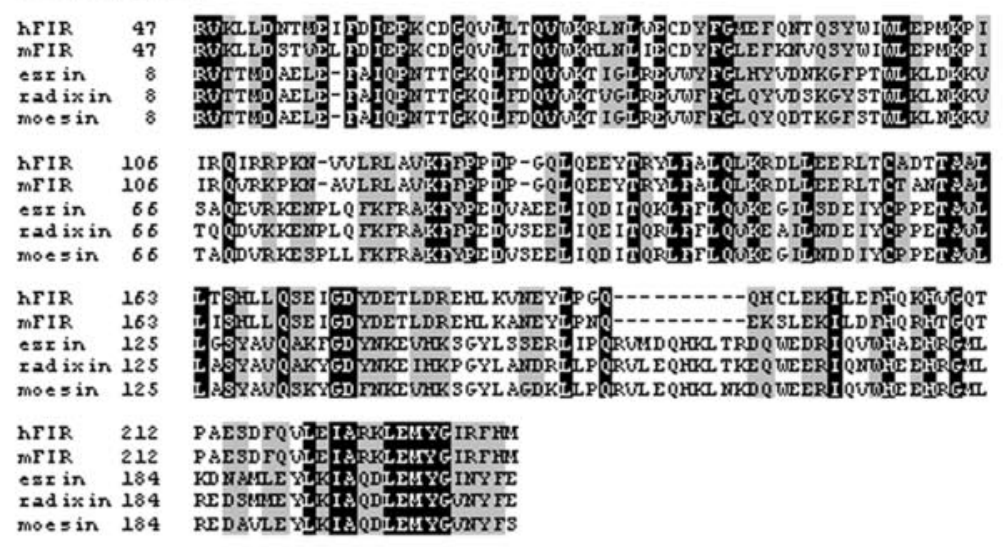

DH domain

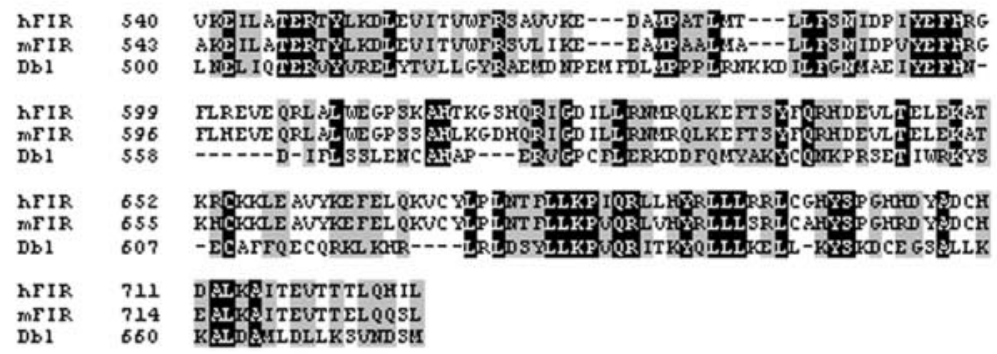

1st PH domain

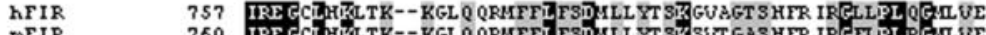

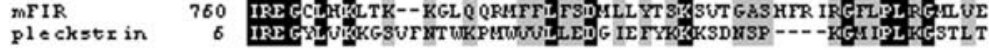

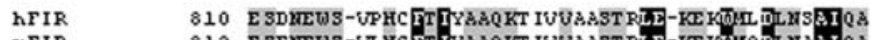

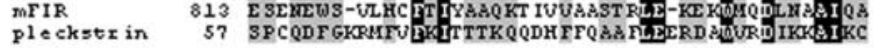

2nd PH domain

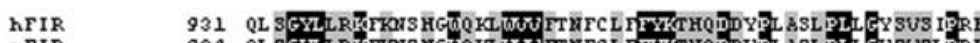
MFIR
P1 ekst $x$ in

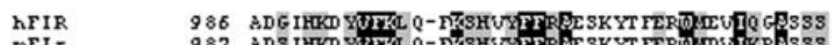

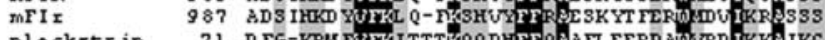

Pleckstr in 71 D FG-KRM TUFKITTT TQODHFFO ATL EERD

hFIR 540

hSOS1 205

hT i $2 \sin 1045$

huav1 199

hFIR 599

h30S1 265

hT i $2 \sin 110$

huav1 256

hFIR 655

hSos1 31

$\mathrm{hT}_{\mathrm{i}} \operatorname{2ml} 116$

huav1 301

hTIR $\quad 712$

hS0S1 376

$\mathrm{hT} i \operatorname{anc} 1120$

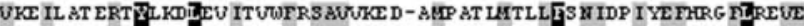

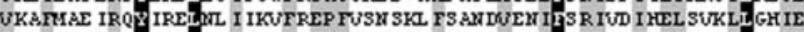

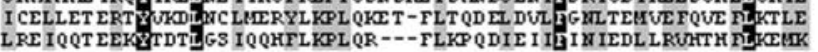

ORI AL WEGPSK AHTKGSHOR--- - IGD ILLRMRROLKC FT SYTFORFEEUL TEL EKATKRC

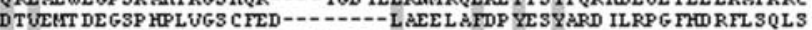
DURLUPDLEKLEKUDQ FKKUL FSL GGSTL YYADR YKL YS AFCA IKTKUP KUL --UKAKT E AL G-TP G AARLYQU--

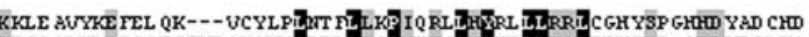
KP GA AL YL QS IGEGTKX AUQYULPRLLL AP UYHCLEY FELLKOLEEK SED-OED KECLK0 DTAFKATL DQUPKQ-- QHS STLESYL IKP IQR IU WYPL LLREL TAL TD AESEE KYKLDV

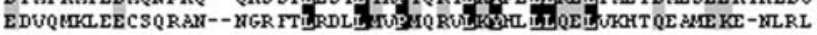

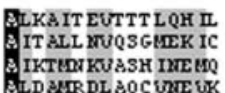

TD ALR DL AOC UNTE

Figure 1 continued. 
A

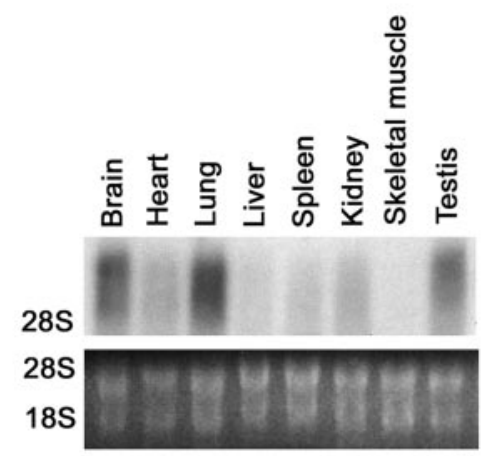

B

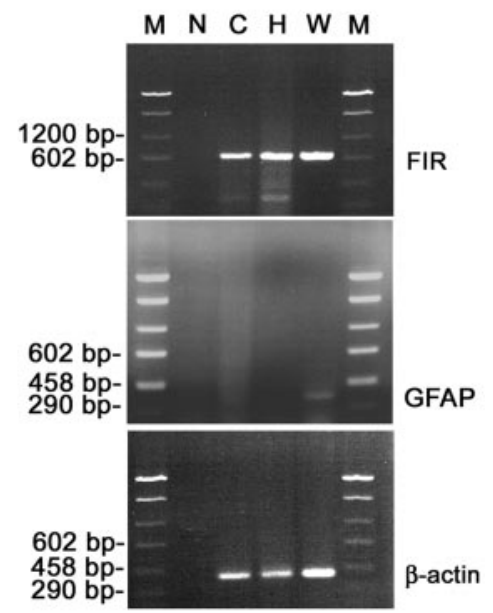

Figure 2. Tissue distribution of FIR and the expression in neurons. $A$, Northern blot analysis of a panel of tissues from adult mouse. Ribosomal RNA was used as a standard. $B$, The expression of mouse FIR mRNA in primary cultured embryonic day 18 hippocampal and cortical neurons was detected by RT-PCR. No signal for GFAP mRNA was found in cortical or hippocampal neurons. $M$, Molecular weight marker; $N$, no cDNA; $C$, cortical neurons; $H$, hippocampal neurons; $W$, adult mouse whole brain.

a putative protein consisting of 1055 amino acids. The proposed initiating ATG conforms to a Kozak consensus sequence (Kozak, 1986), and there is a stop codon just upstream of this ATG in frame (data not shown). The encoded putative protein is predicted to have a core molecular mass of $117 \mathrm{kDa}$ and has highly homologous domains implicated in signal transduction (Fig. 1). We also detected possible homolog of KIAA0793 in Mus musculus (GenBank accession number BC009153), whose putative open reading frame consists of 1065 amino acids (Fig. 1 $A$ ). The putative protein in mouse shows $83 \%$ identity and $97 \%$ similarity with that encoded by KIAA0793 (Fig. $1 A$ ). Each of these putative proteins has one highly conserved $\mathrm{DH}$ domain and two $\mathrm{PH}$ domains. In N-terminal region, they contain an interesting structure exhibiting homology to the FERM domain (band 4.1 homology domain) of ERM proteins (ezrin, radixin, and moesin). The FERM domain is known to associate with plasma membrane proteins such as CD44 (Bretscher et al., 1997; Tsukita et al., 1997; Vaheri et al., 1997) (Fig. 1B). As well established, a tandem of $\mathrm{DH}$ and $\mathrm{PH}$ domains are responsible for the nucleotide exchange activity of Rho GTPases, and, therefore, we tentatively named these newly detected molecules as FERM domain including
RhoGEF (FIR), which might represent a novel exchange factor for Rho GTPases.

\section{Tissue distribution of FIR and the expression in neurons}

We determined the tissue distribution of mouse FIR mRNA to gain insight into possible functional roles. A 800 bp fragment corresponding to mouse FIR (nucleotides 2311-3110) was used to specifically detect FIR mRNA. Northern blot analysis of a panel of tissues from adult mouse revealed an $\sim 8 \mathrm{~kb}$ mRNA species, with high levels of expression in brain, lung, and testis (Fig. 2A). Low levels of expression could be found in heart and kidney. We next examined the expression of FIR mRNA in primary neuronal cultures (1 d after dissociation) derived from embryonic day 18 mice by RT-PCR. In both cortical and hippocampal neurons, the signals corresponding to FIR mRNA were detected (Fig. 2B). These results suggest that FIR may play some roles in neuronal cells in brain.

\section{FIR activates Rac1 but not Cdc42 or RhoA}

To determine the specific Rho GTPases on which FIR can catalyze GDP-GTP exchange, we used an in vitro assay that measured the ability of FIR to induce the dissociation of ${ }^{3} \mathrm{H}$-labeled GDP from RhoA, Rac1, or $\mathrm{Cdc} 42$. As shown in Figure $3 A$, the isolated DH domain promoted nucleotide exchange of Rac1 but not on RhoA or $\mathrm{Cdc} 42$. A fused protein of $\mathrm{DH}$ and $\mathrm{PH}$ domains had the same effects on Rac1 as DH domain itself, suggesting that $\mathrm{PH}$ domain did not enhance nucleotide exchange of Rac1.

Next, we assessed binding of FIR with nucleotide-depleted Rho GTPases. HEK293 cells were transfected with the GFPtagged N-terminal truncated form of FIR, which consists of DH and $\mathrm{PH}$ domains without FERM domain. Purified nucleotidedepleted GST fusion proteins of Cdc42, Rac1, and RhoA were incubated with the lysates from the transfected HEK293 cells. The results show that FIR interacted with nucleotide-depleted Rac1 but not with RhoA or Cdc42 (Fig. 3B). These data support the notion that FIR acts on Rac1.

To examine whether FIR acts as a Rac1-specific GEF also in vivo, we measured the activity for Rac1, RhoA, or Cdc42 in HEK293T cells transiently transfected with or without FIR construct by affinity precipitation. Because Rho GTPases in the GTP-bound state bind to their downstream effectors, GST fusions of these effectors can be used to capture active Rho GTPases from cell lysates. Thus, a GST fusion to the Rac1/Cdc42 binding domain of PAK (GST-PAK2) was used to specifically precipitate GTP-bound Rac1 or Cdc42 from cell extracts (Akasaki et al., 1999). RhoA activity was examined using a GST fusion to the RhoA binding domain of Rhotekin (GST-RBD) (Ren et al., 1999). This assay revealed that extracts of HEK293T cells transfected with Rac1 and FIR contained increased amount of GTP-Rac1 compared with the control cells without FIR expression (Fig. $3 B$ ), although the levels of expression of Rac1 were comparable. As expected, no or little activation of RhoA or Cdc42 could be found (Fig. $3 C$ ).

We further confirmed Rac1 activation by FIR by radioactive in vivo nucleotide labeling. HEK293T cells transiently transfected with HA-tagged Rac1 with or without FIR were ${ }^{32} \mathrm{P}$-labeled, and the radioactivity associated with Rac1 was determined by immunoprecipitation with the anti-HA antibody, followed by thin-layer chromatography. The radioactivity precipitated with Rac1 comigrated with a GDP standard. Because Rho proteins have a high intrinsic GTPase activity, this assay precludes the detection of 

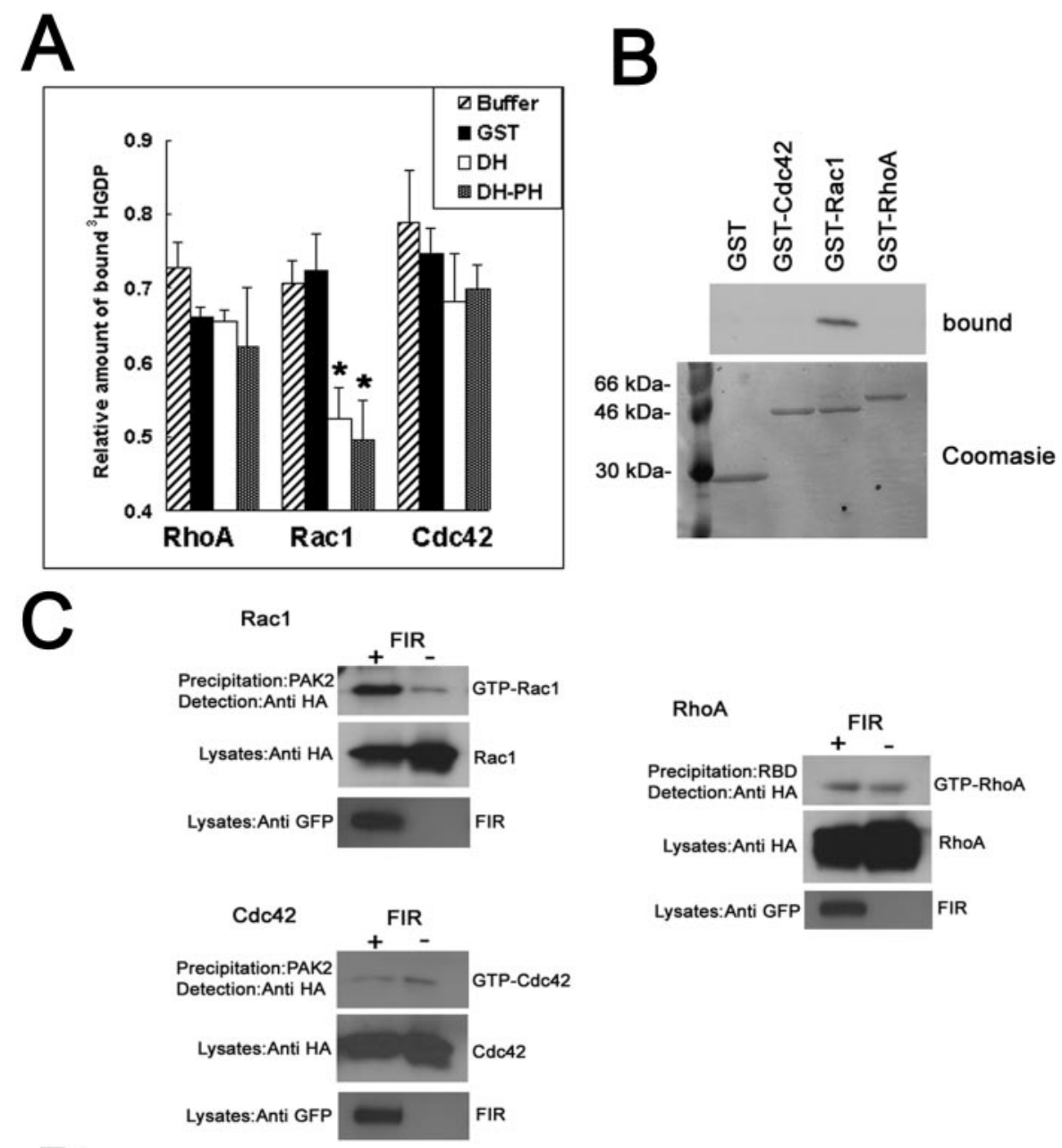

Figure 3. FIR activates Rac1 but not $\mathrm{Cdc} 42$ or RhoA. A, In vitro exchange activity of DH domain of FIR. The ability of DH or DH-PH domain of FIR to induce the dissociation of ${ }^{3} \mathrm{H}$-labeled GDP from RhoA, Rac1, or Cdc42 in 30 min was measured. GST protein or the incubation buffer was used as a control. The graph represents the average $\pm \mathrm{SE}$ of relative amount of initial $\left[{ }^{3} \mathrm{H}\right] \mathrm{GDP}$ remaining bound from three individual experiments. ${ }^{*} p<0.05 ; t$ test, compared with the control. $B$, Binding of the FIR with nucleotide-depleted Rho GTPases. Lysates (1 mg of protein) from the HEK293 cells transfected with GFP- $\Delta$ N-FIR were incubated with $5 \mu \mathrm{g}$ of GST-fused Rho GTPases. Bound proteins were analyzed by Western blotting with the anti-GFP monoclonal antibody. Precipitated GST fusion proteins were visualized with Coomassie blue (bottom). C, Pull-down GTPase activity assays. The activity for Rho GTPases in HEK293T cells transiently cotransfected with HAtagged RhoA and with or without FL-FIR was detected by affinity precipitation using GST fusions of their effectors. The amounts of Rho GTPases in the lysates are shown in the middle panels. FIR expression was confirmed with the anti-GFP antibody (bottom). D, Precipitation of $\left[{ }^{32} \mathrm{P}\right]$ GDP-Rac1. After ${ }^{32} \mathrm{P}$ labeling, HEK293 cells transfected with HA-tagged Rac1 and with or without FIR were immunoprecipitated with the anti-HA antibody. $\left[{ }^{32} \mathrm{P}\right]$ GDP was quantified by scraping the thin-layer plates and counting. Values represent relative amount of radioactivity and are expressed as means \pm SEM of four experiments. $*^{* *} p<0.005 ; t$ test, compared with the control vector. Expression of Rac1 (middle) or FIR (bottom) in the lysates was determined.

radiolabeled GTP and reflects the nucleotide exchange rates of the GTPases (Yamashita et al., 1999). Massive ${ }^{32}$ P-labeled GDP associated with Rac1 was coprecipitated in the presence of FIR, whereas levels were low in the absence of FIR (Fig. 3D). Together, these results demonstrate that the catalytic domain of FIR acts specifically on Rac1 both in vitro and in vivo. In fact, amino acid sequence of DH domain of FIR is highly similar to that of other Rac-GEFs, such as SOS1, Tiam1, and Vav1 (Fig. 1C). Similarity of the putative DH domain of human FIR with that of human SOS1, Tiam1, or Vav1 is $63.2,65.6$, or $61.5 \%$, respectively.

\section{Effects of FIR on the actin cytoskeleton}

We next examined the effects of FIR on the morphology of fibroblasts, in which RhoA, Rac1, and Cdc42 each elicits distinct morphological changes. Specifically, RhoA induces stress fiber formation, Cdc42 induces filopodia extension, and Rac1 induces lamellipodia formation and membrane ruffling (Hall, 1998). We transfected NIH3T3 fibroblasts with the plasmid for GFP-fused FIR or GFP. After serum starvation for $16 \mathrm{hr}$, we detected the expression of FIR by GFP autofluorescence and examined the actin structures by staining F-actin with rhodamine-phalloidin. 


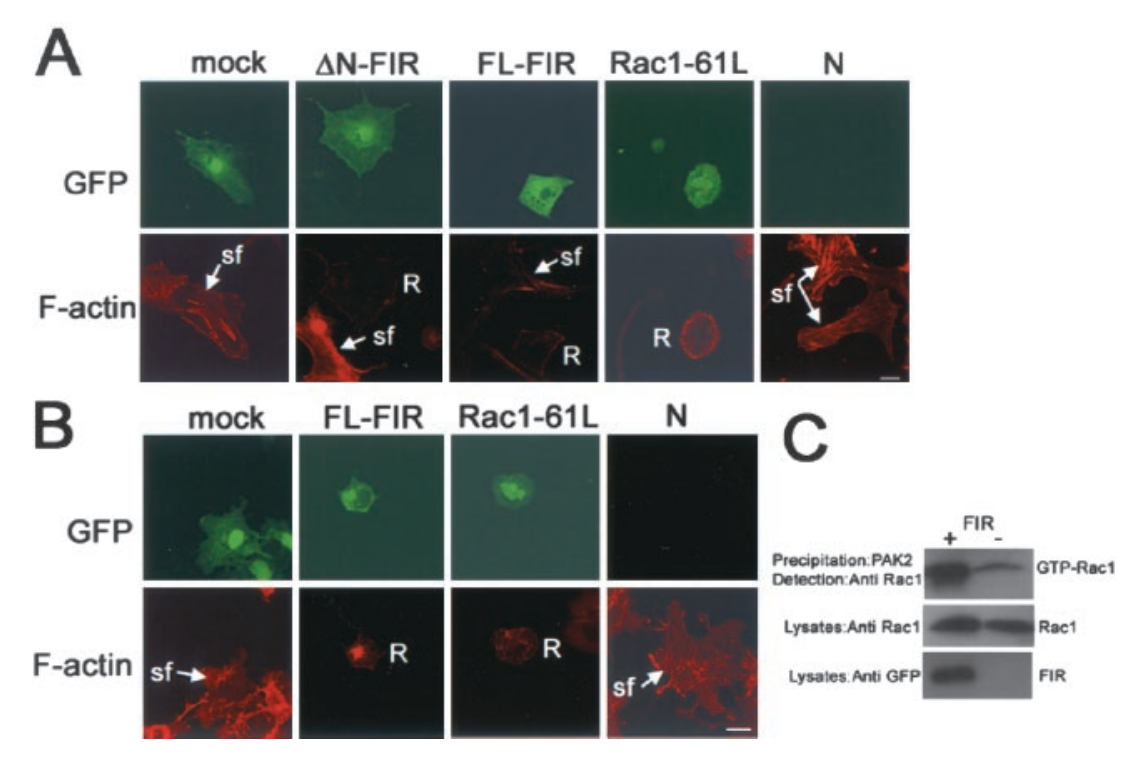

Figure 4. Effects of FIR on the actin cytoskeleton. A, NIH3T3 cells transfected with the full-length FIR and $\mathrm{N}$-terminal truncated FIR displayed lamellipodia and ruffles, indicative of Rac. Scale bar, $50 \mu \mathrm{m}$. B, COS-7 cells transfected with FIR showed similar phenotypic changes induced by Rac1-61L Scale bar, $50 \mu \mathrm{m}$. $C$, Endogenous Rac1 activation by FIR in COS-7 cells was detected using pull-down Rac1 activation assay. $N$, Nontransfected cells; $R$, ruffles; $s f$, stress fibers.

GFP-FL-FIR-transfected cells displayed lamellipodia and ruffles, indicative of Rac (Hall, 1998; Penzes et al., 2000) (Fig. 4A). Stress fiber formation was significantly suppressed in the cells expressing FIR compared with the control cells expressing GFP. These changes in actin cytoskeleton induced by FIR were observed in the cells transfected with the dominant active form of Rac1 (Rac1-61L), consistent with our biochemical data that show activation of Rac1 by FIR. Next, we made a GFP fusion to $\mathrm{N}$-terminal truncated form of FIR, in which FERM domain was deleted, to assess whether FERM domain was not necessary to induce these changes in actin structures. N-terminal truncated FIR also induced morphological changes characteristic of the activation of Rac1. Interestingly, the cells expressing full-length FIR fusion protein, which contains FERM domain, showed a punctate pattern similar to that observed previously for ERM proteins fused to GFP (Mangeat et al., 1999; Olsson et al., 1999), whereas GFP signals for N-terminal truncated FIR were diff use in the cytoplasm (Fig. 4A). Signals for N-terminal truncated FIR were seen in the nucleus, as is the case with Rac1, although function of Rac1 in the nucleus has remained to be elucidated (Kraynov et al., 2000). In contrast, the full-length FIR was mainly localized in the cytoplasm, suggesting that FERM domain may regulate the subcellular localization of FIR.

These alterations of the actin structures by expression of FIR were also found in COS-7 cells (Fig. 5B). Pull-down Rac1 activation assay revealed that endogenous Rac1 was activated in COS-7 cells transiently transfected with FIR compared with the control cells (Fig. 5C). Overall, these results show that FIR regulates the structure of actin cytoskeleton presumably through activation of Rac1.

\section{FIR regulates neuronal morphology}

Because FIR mRNA was expressed in cortical and hippocampal neurons in the developmental stages as well as the adult brain from mice, it is suggested that FIR may play some roles in neuronal function. Therefore, we established an assay to directly address the role of FIR in regulating neuronal morphology. Dissociated culture of embryonic $18 \mathrm{~d}$ rat cortical neurons were transfected with GFP or GFP-fused FIR and cultured in the defined medium for $48 \mathrm{hr}$, and then morphological changes were assessed. Neurons overexpressing the full-length or N-terminal truncated FIR often displayed multiple lateral growth cones extending from neurites compared with those transfected with GFP (Fig. 5A). A large fraction of neurons overexpressing the full-length or N-terminal truncated FIR had growth cones on their cell soma. These alternations in cortical neurons are consistent with the previous finding in which the cortical neurons were transfected with Rac1-specific GEF (Penzes et al., 2001). Similar to the finding in NIH3T3 cells, cortical neurons overexpressing the full-length FIR, which contains FERM domain, showed the punctated pattern, characteristic of ERM proteins.

Next, we evaluated the effects of overexpression of FIR by measuring the total neurite length per neuron and the length of the longest neurite per neuron visualized by autofluorescence. The average length of the longest neurite per full-length FIRexpressing neuron was significantly shorter than that from the GFP control (Fig. $5 A d, A e, B$ ). The average length of the longest neurite per neuron expressing GFP-fused N-terminal truncated FIR was not significantly different from that expressing full-length FIR (data not shown). Exactly the same results were obtained when the total neurite length per neuron was measured (data not shown). Thus, regulation of neurite outgrowth by overexpression of FIR in embryonic cortical neurons may be attributable to $\mathrm{DH}$ and $\mathrm{PH}$ domains of FIR rather than its FERM domain.

\section{Neurite remodeling by FIR is dependent on activation of Rac1}

The effects of FIR on the neuronal morphology may be attributable to Rac1 activation. To test this hypothesis, we used mammalian expression vectors for constitutive active and dominant negative forms of Rac1 (Ridley and Hall, 1992; Nobes and Hall, 1995). Cortical neurons were transfected with constitutive active Rac1 (Rac1-61L). The average length of the longest neurite per neuron expressing Rac1-61L was significantly shorter than the control (Figs. 5B, 6A), demonstrating that the effect of Rac1-61L was comparable with that of FIR. On the other hand, ectopic expression of the dominant negative mutant of Rac1 (Rac1-17N) blocked the effect of FIR with regard to the neurite outgrowth (Figs. $5 B$, $6 A$ ). We further tested whether RhoA or Cdc42 was involved in FIR signaling. However, cotransfection of dominant negative RhoA (RhoA-19N) did not modify the effect of FIR (Figs. 5B, 6B). Coexpression of FIR with CRIB domain of NWASP, which was used to competitively inhibit Cdc42 (Miki et al., 1998), also failed to affect the morphology induced by FIR (Figs. 5B, 6B). These 
A
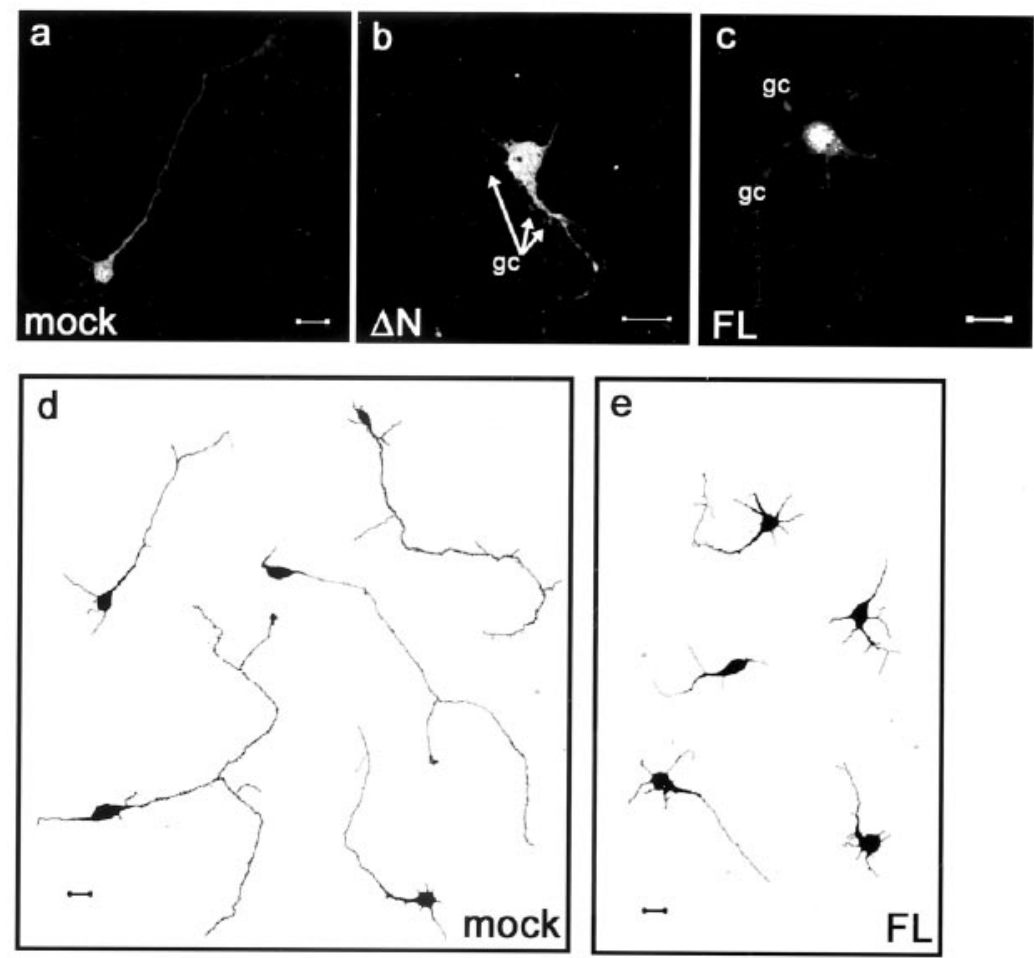

B
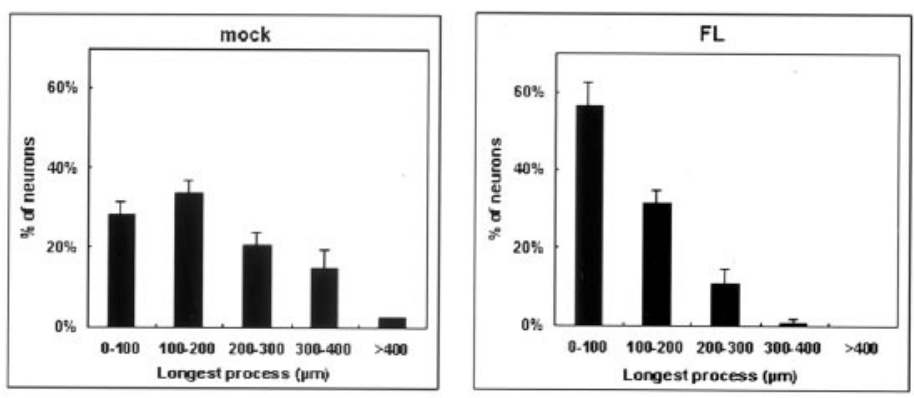

Figure 5. FIR regulates neuronal process length. $A$, Cortical neurons ( $2 \mathrm{~d}$ after dissociation) were transfected with the empty pEGFP vector $(a)$, pEGFP- $\Delta$ N-FIR $(b)$, or pEGFP-FL-FIR $(c)$. Transfected cells were detected by GFP autofluorescence. Neurons overexpressing FLFIR or $\Delta$ N-FIR display multiple lateral growth cones extending from neurites and growth cones on their cell soma. Computer-assisted tracing of $\beta$-tubulin III-labeled neurites of control GFP $(c)$ - and FL-FIR $(d)$-expressing neurons revealed apparent difference between two groups. Scale bar, $20 \mu \mathrm{m}$. B, The length of the longest process in each FL-FIR- or GFP-expressing neurons was analyzed. Histograms of lengths of the longest process of transfected neurons. For $B$, error bars are the SE for three experiments, each containing 40-50 neurons. Overexpression of FIR affects the length of neurites. FL, Fulllength; $g c$, growth cones. data demonstrate that FIR regulates neurite remodeling of the dissociated cortical neurons through activation of Rac1.

\section{DISCUSSION}

The GEFs from the Dbl family are multifunctional molecules that transduce diverse intracellular signals leading to the activation of Rho GTPases. The tandem of DH and PH domains shared by all members of this family represent the structural module responsible for catalyzing the GDP-GTP exchange reaction of Rho GTPases. Recent progress in genomic, genetic, structural, and biochemical studies have implicated GEFs from Dbl family members in diverse biological processes, including growth and development, tissue organization, and neuronal axon guidance. In the nervous system, Rho GTPases are essential for establishing highly asymmetrical neuronal forms and might adjust the shape of neurites in differentiated neurons (Zhai et al., 2001). This notion is substantiated by the facts that expression of dominant inactive forms of Rac1 and Cdc42 caused defects in axon guidance and cell migration in C. elegans, Drosophila, and mouse (Luo, 2000). Among many regulators of Rho GTPases, Trio and ephexin, GEFs for Rho GTPases, have emerged recently as key factors for axon guidance (Bateman et al., 2000; Shamah et al., 2001). Trio and ephexin associate with the receptor phosphatase LAR and EphA, respectively, and transduce the signal from these receptors to Rho GTPases. However, because at least these GEFs seem to mediate signals from the specific receptors and there are much more guidance receptors, identified so far, whose molecular signals remain to be elucidated, new molecules will be added in the course of elucidation of the mechanisms of neuronal navigation in the future. We identified a previously uncharacterized GEF for Rac and named FERM domain including RhoGEF (FIR), which would be implicated in axon guidance, because FIR mRNA is expressed in cortical and hippocampal neurons during the developmental stages. FIR shares mild homology with CDEP (chondrocyte-derived ezrin-like domain-containing protein), which has a FERM domain at the $\mathrm{N}$ terminus and a DH domain followed by two $\mathrm{PH}$ domains in the $\mathrm{C}$-terminal region (Koyano et al., 1997, 2001). However, CDEP was reported to act on Rho in vitro, and the distribution pattern was different from FIR, suggesting distinct function of CDEP. To clearly elucidate the spe- 
A
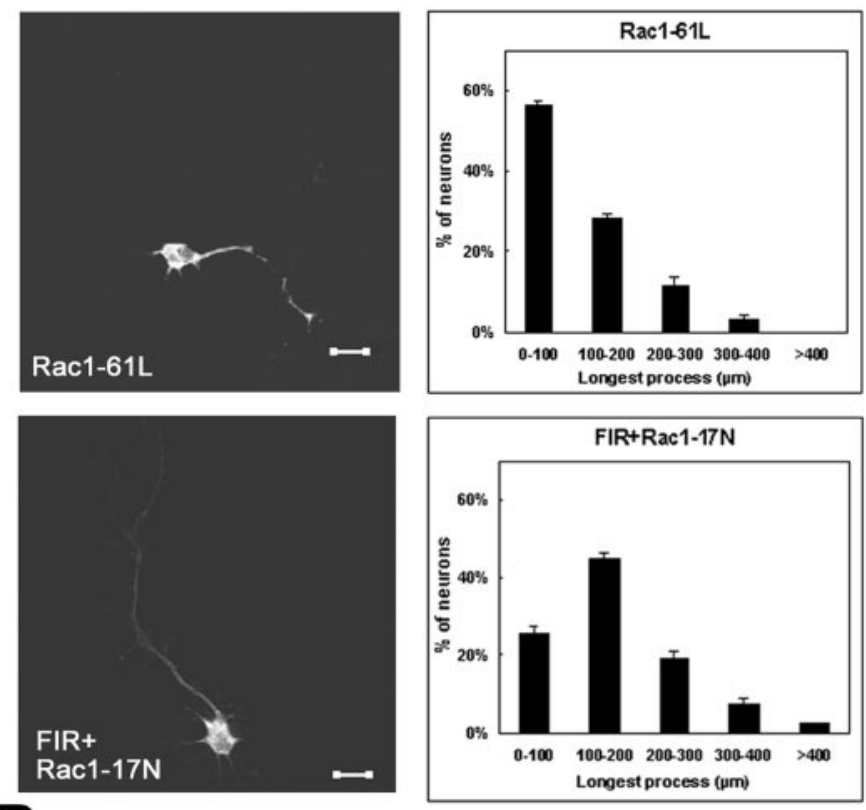

D

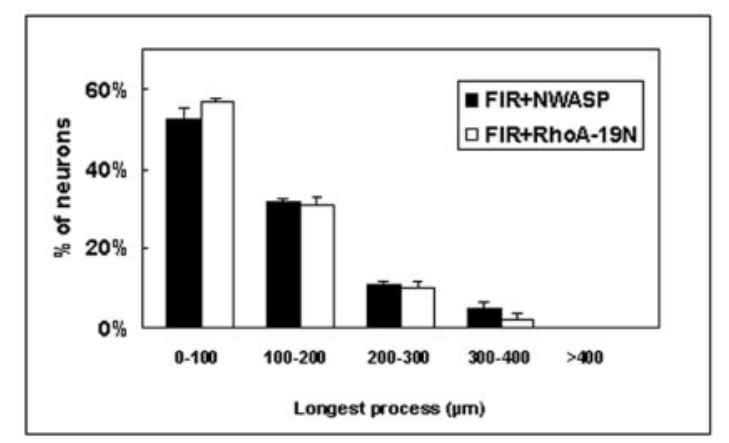

Figure 6. Neurite remodeling by FIR is involved in Rac1 signaling. $A$, Cortical neurons expressing Rac1-61L (top) or Rac1-17N plus FIR (bottom). Transfected cells were detected by GFP autofluorescence. $B$, The length of the longest process in each neuron expressing FIR plus NWASP or FIR plus RhoA-19N was analyzed. Histograms of the length of the longest process of the transfected neuron. For $A$ and $B$, error bars are SE from three experiments, each containing 40-50 neurons.

cific roles of these GEFs, it will be necessary to find the interactors of FIR to find how FIR is regulated in the cells.

Previous reports have shown diverse effects of Rho GTPases on neuronal morphology (Luo et al., 1994; Li et al., 2000). Activated Rac1 inhibited axonal outgrowth of both Drosophila sensory and mouse Purkinje neurons (Luo et al., 1994; Luo et al., 1997), suppressed axonal formation in Xenopus retinal ganglion cells (Ruchhoeft et al., 1999), and elicited growth cone collapse in embryonic chick dorsal root ganglion neurons (Jin and Strittmatter, 1997). Penzes et al. (2001) showed shortened axons and excessive growth cones of rat cortical neurons, mediated by Rac1specific catalytic domain of RhoGEF protein, Kalirin-9. The inhibition of neurite elongation and morphological changes by overexpression of FIR in rat cortical neurons through Rac1 activation are consistent with these previous reports showing Rac1 phenotype. However, the effects of any DH domain might depend on the complement of Rho GTPases present in any given neuron at a particular time (Penzes et al., 2001). In addition, the action of Rho GTPases might vary with cell type and developmental stage. For example, we found that axonal outgrowth was facilitated through inactivation of RhoA and inhibited by activation of RhoA in other cells, such as embryonic chick ciliary neurons, cerebellar granule neurons, and hippocampal neurons (Yamashita et al., 1999; Neumann et al., 2002; Yamashita et al., 2002), that are seemingly contradictory. Therefore, FIR may mediate diverse actions that are dependent on the cell context.

Many Rho GTPase-specific GEFs contain multiple protein motifs involved in intracellular signal transduction, such as Src homology domains and PDZ domains (Matsuo et al., 2002). FIR includes the FERM domain. ERM proteins, collectively composed of ezrin, radixin, and moesin, are a group of closely related membrane cytoskeleton linkers that regulate cell adhesion and cortical morphogenesis (Mangeat et al., 1999). The N-terminal membrane binding domain, the so-called FERM domain, of FERM has been shown to associate with several membrane associated proteins, such as hyaluronan receptor CD44 (Tsukita et al., 1994), intercellular adhesion molecule (ICAM-1), and ICAM-2 (Heiska et al., 1998). Therefore, considering the fact that Rho regulators play important roles in neuronal navigation, it is possible that FIR transmits signals from plasma membrane receptors for guidance molecules to cytoskeletal reorganization through interaction of FERM domain with the receptors. In fact, Max-1, a recently identified cytoplasmic protein that has FERM domain, was shown to be involved in netrin-induced axonal guidance by modulating the Unc5 receptor signaling pathway (Huang et al., 2002). In addition, FERM proteins themselves are also known as upstream regulators of RhoA, and their FERM domain can bind directly with $\mathrm{PH}$ domain of Dbl (Mangeat et al., 1999; Tsukita and Yonemura, 1999; Louvet-Vallee, 2000). Thus, the FERM domain of FIR may elicit Rho signal through binding to Dbl, independent of the internal DH domain. Alternatively, it is possible that FERM domain and the internal $\mathrm{PH}$ domains might mutually interact intramolecularly and regulate additional transductional functions for the cytoskeleton. Detailed structurefunction analyses of FIR should help to elucidate the precise mechanism of FIR in regulating cell morphology, especially in neurons.

\section{REFERENCES}

Akasaki T, Koga H, Sumimoto H (1999) Phosphoinositide 3-kinasedependent and -independent activation of the small GTPase Rac2 in human neutrophils. J Biol Chem 274:18055-18059.

Awasaki T, Saito M, Sone M, Suzuki E, Sakai R, Ito K, Hama C (2000) The Drosophila trio plays an essential role in patterning of axons by regulating their directional extension. Neuron 26:119-131.

Bateman J, Shu H, Van Vactor D (2000) The guanine nucleotide exchange factor trio mediates axonal development in the Drosophila embryo. Neuron 26:93-106

Boguski MS, McCormick F (1993) Proteins regulating Ras and its relatives. Nature 366:643-654.

Bretscher A, Reczek D, Berryman M (1997) Ezrin: a protein requiring conformational activation to link microfilaments to the plasma membrane in the assembly of cell surface structures. J Cell Sci 110:3011-3018

Chuang TH, Xu X, Kaartinen V, Heisterkamp N, Groffen J, Bokoch GM (1995) Abr and Bcr are multifunctional regulators of the Rho GTPbinding protein family. Proc Natl Acad Sci USA 92:10282-10286.

Fukuhara S, Murga C, Zohar M, Igishi T, Gutkind JS (1999) A novel PDZ domain containing guanine nucleotide exchange factor links heterotrimeric G proteins to Rho. J Biol Chem 274:5868-5879.

Hall A (1998) Identification of two distinct mechanisms of phagocytosis controlled by different Rho GTPases. Science 279:509-514.

Heiska L, Alfthan A, Gronholm M, Vilja P, Vaheri A, Carpen O (1998) Association of ezrin with intercellular adhesion molecule-1 and -2 (ICAM-1 and ICAM-2). Regulation by phosphatidylinositol 4, 5-bisphosphate. J Biol Chem 273:21893-21900. 
Horii Y, Beeler JF, Sakaguchi K, Tachibana M, Miki T (1994) A novel oncogene, ost, encodes a guanine nucleotide exchange factor that potentially links Rho and Rac signaling pathways. EMBO J 13: $4776-4786$.

Huang X, Cheng HJ, Tessier-Lavigne M, Jin Y (2002) Max-1, a novel $\mathrm{PH} / \mathrm{MyTH}$ /FERM domain cytoplasmic protein implicated in netrinmediated axon repulsion. Neuron 34:563-576.

Jin Z, Strittmatter SM (1997) Rac1 mediates collapsin-1-induced growth cone collapse. J Neurosci 17:6256-6263.

Koyano Y, Kawamoto T, Shen M, Yan W, Noshiro M, Fujii K, Kato Y (1997) Molecular cloning and characterization of CDEP, a novel human protein containing the ezrin-like domain of the band 4.1 superfamily and the Dbl homology domain of Rho guanine nucleotide exchange factors. Biochem Biophys Res Commun 241:369-375.

Koyano Y, Kawamoto T, Kikuchi A, Shen M, Kuruta Y, Tsutsumi S, Fujimoto K, Noshiro M, Fujii K, Kato Y (2001) Chondrocyte-derived ezrin-like domain containing protein (CDEP), a rho guanine nucleotide exchange factor, is inducible in chondrocytes by parathyroid hormone and cyclic AMP and has transforming activity in NIH3T3 cells. Osteoarthritis Cartilage 9:S64-S68.

Kozak M (1986) Point mutations define a sequence flanking the AUG initiator codon that modulates translation by eukaryotic ribosomes. Cell 31:283-292.

Kraynov VS, Chamberlain C, Bokoch GM, Schwartz MA, Slabaugh S, Hahn KM (2000) Localized Rac activation dynamics visualized in living cells. Science 290:333-337.

Kunda P, Paglini G, Quiroga S, Kosik K, Caceres A (2001) Evidence for the involvement of Tiam1 in axon formation. J Neurosci 21:2361-2372.

Lamarche N, Hall A (1994) GAPs for rho-related GTPases. Trends Genet 10:436-440.

Li Z, van Aelst L, Cline HT (2000) Rho GTPases regulate distinct aspects of dendritic arbor growth in Xenopus central neurons in vivo. Nat Neurosci 3:217-225.

Liebl EC, Forsthoefel DJ, Franco LS, Sample SH, Hess JE, Cowger JA, Chandler MP, Shupert AM, Seeger MA (2000) Dosage-sensitive, reciprocal genetic interactions between the Abl tyrosine kinase and the putative GEF trio reveal trio's role in axon pathfinding. Neuron 26:107-118.

Louvet-Vallee S (2000) ERM proteins: from cellular architecture to cell signaling. Biol Cell 92:305-316.

Luo L (2000) Rho GTPases in neuronal morphogenesis. Nat Rev Neurosci 1:260-264.

Luo L, Liao YJ, Jan LY (1994) Distinct morphogenetic functions of similar small GTPases: Drosophila Drac1 is involved in axonal outgrowth and myoblast fusion. Genes Dev 8:1787-1803.

Luo L, Jan LY, Jan YN (1997) Rho family GTP-binding proteins in growth cone signalling. Curr Opin Neurobiol 7:81-86.

Mackay DG, Hall A (1998) Rho GTPases. J Biol Chem 273: 20685-20688.

Mangeat P, Roy C, Martin M (1999) ERM proteins in cell adhesion and membrane dynamics. Trends Cell Biol 9:187-192.

Matsuo N, Hoshino M, Yoshizawa M, Nabeshima Y (2002) Characterization of STEF, a guanine nucleotide exchange factor for Rac1, required for neurite growth. J Biol Chem 277:2860-2868.

Miki H, Sasaki T, Takai Y, Takenawa T (1998) Induction of filopodium formation by a WASP-related actin-depolymerizing protein N-WASP. Nature 391:93-96.

Neumann H, Schweigreiter R, Yamashita T, Rosenkranz K, Wekerle H, Barde YA (2002) Tumor necrosis factor inhibits neurite outgrowth and branching of hippocampal neurons by a rho-dependent mechanism. J Neurosci 22:854-862.

Newsome TP, Schmidt S, Dietzl G, Keleman K, Asling B, Debant A, Dickson BJ (2000) Trio combines with dock to regulate Pak activity during photoreceptor axon pathfinding in Drosophila. Cell 101: 283-294.

Nobes CD, Hall A (1995) Rho, Rac, and Cdc42 GTPases regulate the assembly of multimolecular focal complexes associated with actin stress fibers, lamellipodia, and filopodia. Cell 81:53-62.

Olsson P, Korhonen L, Mercer EA, Lindholm D (1999) MIR is a novel ERM-like protein that interacts with myosin regulatory light chain and inhibits neurite outgrowth. J Biol Chem 274:36288-36292.

Penzes P, Johnson RC, Alam MR, Kambampati V, Mains RE, Eipper BA (2000) An isoform of kalirin, a brain-specific GDP/GTP exchange factor, is enriched in the postsynaptic density fraction. J Biol Chem 275:6395-6403.

Penzes P, Johnson RC, Kambampati V, Mains RE, Eipper BA (2001) Distinct roles for the two Rho GDP/GTP exchange factor domains of kalirin in regulation of neurite growth and neuronal morphology. J Neurosci 21:8426-8434.

Ren XD, Kiosses WB, Schwartz MA (1999) Regulation of the small GTP-binding protein Rho by cell adhesion and the cytoskeleton. EMBO J 18:578-585.

Richnau N, Aspenstrom P (2001) Rich, a rho GTPase-activating protein domain-containing protein involved in signaling by $\mathrm{Cdc} 42$ and Rac1. J Biol Chem 276:35060-35070.

Ridley AJ, Hall A (1992) The small GTP-binding protein regulates the assembly of focal adhesions and actin stress fibers in response to growth factors. Cell 70:389-399.

Ruchhoeft ML, Ohnuma S, McNeill L, Holt CE, Harris WA (1999) The neuronal architecture of Xenopus retinal ganglion cells is sculpted by rho-family GTPases in vivo. J Neurosci 19:8454-8463.

Shamah SM, Lin MZ, Goldberg JL, Estrach S, Sahin M, Hu L, Bazalakova M, Neve RL, Corfas G, Debant A, Greenberg ME (2001) EphA receptors regulate growth cone dynamics through the novel guanine nucleotide exchange factor ephexin. Cell 105:233-244.

Stam JC, Collard JG (1999) The DH protein family, exchange factors for Rho-like GTPases. Prog Mol Subcell Biol 22:51-83.

Steven R, Kubiseski TJ, Zheng H, Kulkarni S, Mancillas J, Ruiz Morales A, Hogue CW, Pawson T, Culotti J (1998) UNC-73 activates the Rac GTPase and is required for cell and growth cone migrations in $C$. elegans. Cell 92:785-795.

Threadgill R, Bobb K, Ghosh A (1997) Regulation of dendritic growth and remodeling by Rho, Rac, and Cdc42. Neuron 19:625-634.

Tsukita S, Yonemura S (1999) Cortical actin organization: lessons from ERM (ezrin/radixin/moesin) proteins. J Biol Chem 274:34507-34510.

Tsukita S, Oishi K, Sato N, Sagara J, Kawai A, Tsukita S (1994) ERM family members as molecular linkers between the cell surface glycoprotein CD44 and actin-based cytoskeletons. J Cell Biol 126:391-401.

Tsukita S, Yonemura S, Tsukita S (1997) ERM proteins: head-to-tail regulation of actin-plasma membrane interaction. Trends Biochem Sci 22:53-58.

Vaheri A, Carpen O, Heiska L, Helander TS, Jaaskelainen J, MajanderNordenswan P, Sainio M, Timonen T, Turunen O (1997) The ezrin protein family: membrane-cytoskeleton interactions and disease associations. Curr Opin Cell Biol 9:659-666.

van Aelst L, D'Souza-Schorey C (1997) Rho GTPases and signaling networks. Genes Dev 11:2295-2322.

Whitehead IP, Campbell S, Rossman KL, Der CJ (1997) Dbl family proteins. Biochim Biophys Acta 1332:F1-F23.

Yamashita T, Tucker KL, Barde YA (1999) Neurotrophin binding to the p75 receptor modulates Rho activity and axonal outgrowth. Neuron 24:585-593

Yamashita T, Higuchi H, Tohyama M (2002) The p75 receptor transduces the signal from myelin-associated glycoprotein to Rho. J Cell Biol 157:565-570.

Zalcman G, Dorseuil O, Garcia-Ranea JA, Gacon G, Camonis J (1999) RhoGAPs and RhoGDIs, (His)stories of two families. Prog Mol Subcell Biol 22:85-113.

Zhai J, Lin H, Shamim M, Schlaepfer WW, Canete-Soler R (2001) Identification of a novel interaction of 14-3-3 with p190RhoGEF. J Biol Chem 276:41318-41324. 